\section{Orthopaedic Management of Spina Bifida Cystica}

By Malcolm B. Menelaus. Pp. 116, illustrated. Edinburgh and London: E. \& S. Livingstone, 1971. £3.00.

In recent years our whole attitude to patients with spina bifida has been radically transformed. The emphasis today is on early closure of the defect, valvular control of hydrocephalus and an aggressive policy towards urogenital and orthopaedic problems. Rapid changes imply new techniques and there is indeed much for every orthopaedic surgeon or trainee to learn in this field.

Mr Menelaus' book fills this need admirably. It is easy to read, unambiguous in style and full of sensible practical advice. The main bulk of the book deals with the numerous orthopaedic deformities which play such a large part in the management. But the appendices are almost as valuable; they include an analysis of the results of treating 430 patients, an account of a multi-disciplinary spına bifida clinic (so essential in treatment), and some splendidly helpful notes for parents of spina bifida children.

The author is to be congratulated on producing an excellent book which deserves to be very widely read.

\section{Surgeons' Decisions}

By Professor H. L. DuthiE. Pp. 112, illustrated. Edinburgh: Oliver \& Boyd, 1971. 37 $\frac{1}{2}$ p.

Surgeons are inclined to scoff at books written for the layman-even if the layman is assumed to be intelligent. I wonder why. Do they feel that surgical ideas are too sophisticated to be expressed simply, or are they afraid of damaged dignity-the pricking of the bubble of professional pride?

Professor Duthie's book explaining the bases of surgical decisions is an admirable corrective to lofty attitudes. He achieves simplicity without talking down to the reader; his writing is perfectly clear without falsifying the facts; and he covers a wide field without excessive generalization. Although the book is designed for non-medical readers, there can be few doctors who would fail to benefit from reading it. They are likely to gather a certain amount of information from which over-specialization has protected them; but, much more important, they may well learn how to communicate accurately yet in a simple manner devoid of pomposity. This book can thoroughly be recommended to a very wide public.

\section{Emergencies in Medical Practice}

Edited by C. Allan Birch. Ninth edition. Pp. 782, ninety five figures. Edinburgh and London: Churchill Livingstone, 1971. £6.00.

We are indeed fortunate that although Dr Allan Birch has retired he has not abandoned the arduous task of keeping his invaluable book up-to-date; in fact, he has done more, he has enlarged it and greatly widened its scope by getting eight distinguished new contributors to write new sections. One of these is a chapter on Resuscitation by Dr Sherwood Jones and there are others which are equally valuable, as well as chapters on Practical Procedures and on Medico-legal and other Non-clinical Emergencies that greatly increase the practical value of the book. Eighteen appendices cover many subjects not commonly dealt with in reference books, giving extremely practical information on Poisons Services, Hyperbaric Oxygen, Renal Dialysis and Respiratory Units, Blood Products, Vaccines and Sera, and details of International Aid Removal by Helicopter and the Samaritans, amongs 5 others. This book is a gold mine of practical, helpful infor $\frac{\mathbb{C}}{\vec{D}}$ mation which every Medical Centre and Hospital Librarye should have freely available, while it will be a valuable in $\Omega$ vestment for any practising doctor. 